\title{
Introduction: Proceedings of the 36th annual meeting of the Society for Exact Philosophy
}

\section{Syntax and the Void!}

\author{
Marc A. Moffett
}

Received: 10 February 2009 / Accepted: 10 February 2009 / Published online: 10 March 2009 (C) Springer Science+Business Media B.V. 2009

The present volume of Synthèse is dedicated to a sampling of papers presented at the 36th annual meeting of The Society for Exact Philosophy, held May 13-18th at the University of Wyoming. Founded in 1970, the inaugural meeting was organized by Mario Bunge at McGill University (see Pelletier 1991 for a detailed discussion of the history of the S.E.P.). Since that time, the meetings have alternated between the United States and Canada and attract a multi-national contingent of researchers with a philosophically diverse range of interests; the Society currently boasts a membership of over 400 philosophers and cognitive scientists.

The S.E.P. is committed to providing a forum for researchers who "believe that rigorous methods have a place in philosophical investigations" (<http://www.phil.ufl. edu/SEP/geninfo.html>). Perhaps the best general statement of the ideology of the Society is the following passage from Frege, a passage that might be said to mark the beginning of the modern era of exact philosophy:

I believe that I can best make the relation of my ideography to ordinary language clear if I compare it to that which the microscope has to the eye. Because of the range of its possible uses and the versatility with which it can adapt to the most diverse circumstances, the eye is far superior to the microscope. Considered as an optical instrument, to be sure, it exhibits many imperfections, which ordinarily remain unnoticed only on account of its intimate connection with our mental life. But, as soon as scientific goals demand great sharpness of resolution, the eye proves to be insufficient. The microscope, on the other hand, is perfectly suited to precisely such goals, but that is why it is useless for all others (Frege 1879[1967], p. 6).

\footnotetext{
M. A. Moffett $(\bowtie)$

Department of Philosophy, College of Arts and Sciences, University of Wyoming, Department 3392, 1000 E. University Ave, Laramie, WY 82071, USA

e-mail: moffett@uwyo.edu
} 
The fruitfulness of Frege's approach is well-known. Not only was his Begriffsschrift a monumental technical achievement, it was a case study in how our understanding of philosophical problems could be advanced by the application of those technical devices.

Indeed, arguably there are two, complementary notions of exact philosophy stemming from Frege's work. On one way of understanding it, exact philosophy concerns the philosophical/theoretical investigation of the foundations of the exact or formal sciences (e.g., logic, mathematics, probability theory, and their application to the natural sciences). In the present volume, this is the conception primarily at work in three of the papers: Chihara's paper on nominalist philosophy of mathematics, Maier and Nute's paper on defeasible logic, and Dean and Kurokawa's paper on the Knowability Paradox. The other operative notion of exact philosophy is the application of those formal methods to standing philosophical problems. It is this second conception which is most prevelant in Forbes's, "Intensional Verbs in Event Semantics" and Pelczar's, "Presentism, Eternalism, and Phenomenal Change." Bridging these two conceptions of exact philosophy is traditional work in analytic philosophy more broadly construed, which helps drive the development of exact methods to account for an increasingly rich array of phenomena. So understood, the relationship between exact philosophy and general analytic philosophy is symbiotic, with general philosophy often serving to reveal the limitations or conceptual blinders of our current formalizations. One nice example of this type of mutualism in the present volume is in Willer's counterexample to modus ponens which exploits insights from Moore's Paradox.

Past proceedings of the S.E.P.have appeared on a one off basis in a variety of journals, including the Journal of Philosophical Logic, Philosophia, Philosophical Studies, and Topoi. The present volume, however, represents what is hoped to be an abiding collaboration between Synthèse and the S.E.P. The editor would like to thank all those who refereed papers both for the original conference and the present volume.

\section{References}

Frege, G. (1879) [1967]. Begriffsschrift, a formula language, modeled upon that of arithmetic, for pure thought. In: J. van Heijenoort (Ed.), From Frege to Gödel. Cambridge: Harvard University Press.

Pelletier, F. J. (1991). The society for exact philosophy. Ruch Filozoficzny, 48, 107-118. 